\title{
Gastric Mucinous Adenocarcinoma
}

National Cancer Institute

\section{Source}

National Cancer Institute. Gastric Mucinous Adenocarcinoma. NCI Thesaurus. Code C5248.

A variant of gastric adenocarcinoma with more than half of the tumor containing extracellular mucinous pools. 